\title{
EXPERIÊNCIAS SIGNIFICATIVAS DE LEITURA E ESCRITA DO TEXTO LITERÁRIO NO IFPB
}

\section{SIGNIFICANT EXPERIENCES OF READING AND WRITING OF THE LITERARY TEXT IN THE IFPB}

\author{
Sayonara Abrantes de Oliveira Uchoa* \\ Symara Abrantes Albuquerque de Oliveira Cabral ${ }^{* *}$ \\ Henrique Miguel de Lima Silva***
}

\begin{abstract}
Resumo: O presente estudo apresenta relato de experiência resultado de intervenção didática voltada ao letramento literário e de como esta prática contribui para o desenvolvimento das habilidades de leitura e escrita no Ensino Médio, atividade fundamental ao desenvolvimento integral dos alunos dos cursos integrados do IFPB. Surge da necessidade de ressignificar o ensino de leitura e escrita na modalidade integrada à formação profissional, por entender que o perfil desse aluno requer um ensino de língua que transcenda a percepção instrumental. Para tal, é descrito o percurso trilhado durante a prática de intervenção, fundamentada na intersecção de contribuições teóricas das áreas de leitura, numa visão interativa, do letramento literário, como também do Método Recepcional de Ensino de Literatura. Organizado em seções que contemplam, concomitantemente, a revisão de literatura e a descrição do percurso trilhando durante a atividade interventiva. Trata-se de uma pesquisa de campo, de intervenção, desenvolvida no IFPB - Cajazeiras. Os resultados apontam para as contribuições dos estudos literários direcionados pela intervenção didática e com bases teóricas pertinentes para o desenvolvimento das habilidades de leitura e escrita no Ensino Médio.
\end{abstract}

Palavras-chave: Ensino. Leitura. Escrita. Letramento literário. Literatura no Ensino Médio.

\begin{abstract}
The present study presents an experience report resulting from didactic intervention focused on literary literacy and how this practice contributes to the development of reading and writing skills in high school, an activity fundamental to the integral development of students of the integrated courses of the IFPB. It arises from the need to resignify the teaching of reading and writing in the modality integrated to professional training, because it understands that the profile of this student requires a language teaching that transcends instrumental perception. To this end, the path taken during the intervention practice is described, based on the intersection of theoretical contributions from the reading areas, in an interactive view, of literary literacy, as well as the Receptive Method of Teaching Literature. Organized in sections that contemplate, concomitantly, the literature review and the description of the path trailing during the interventional activity. This is a field research, intervention, developed at IFPB Cajazeiras. The results point to the contributions of literary studies, directed on the basis of relevant theoretical bases, to the development of reading and writing skills in high school.
\end{abstract}

Keywords: Teaching. Reading. Writing. Literary literacy. Literature in high school.

\footnotetext{
* Docente no IFPB - Campus Cajazeiras. Pós-doutorado em Ensino (UERN), doutorado e mestrado em Linguística (UFPB), graduação em Letras (UFCG). Líder do Grupo de Pesquisa em ensino e aprendizagem de língua (GRENAL) IFPB/CNPQ. E-mail: sayonara.uchoa@ifpb.edu.br

${ }^{* *}$ Graduada em Letras pelo IFPB. Mestre em Sistemas Agroindustriais (UFCG). Membro do Grupo de Pesquisa em Ensino e Aprendizagem em Línguas (GRENAL).E-mail: symara_abrantes@hotmail.com *** Docente do Departamento de Linguística e Língua Portuguesa (UFPB). Doutor e mestre em Linguística (UFPB). Graduado em Letras (FUNESO), Membro do Grupo de Pesquisa em Ensino e Aprendizagem em Línguas (GRENAL). E-mail: henrique.miguel.91@hotmail.com
} 


\section{Introdução}

Os Institutos Federais de Educação, Ciência e Tecnologia, presentes em todo o território brasileiro, consistem em um ambiente educacional complexo e diferenciado, pois visam atender as demandas diversas de uma sociedade em constante mudança através de cursos de nível médio integrado ao profissional, como também os cursos de nível superior. Trata-se, pois, de um ambiente no qual a atmosfera da formação profissional destaca-se, o que lança, muitas vezes, um olhar questionador dessas áreas em relação às disciplinas da base geral que se limitaram a um caráter "instrumental".

Todavia, é importante ressaltar que muitas mudanças já ocorreram em relação a esse panorama educacional. Um novo olhar é lançado vislumbrando um profissional cuja formação não esteja permeada apenas pelos conhecimentos específicos de sua área. Nesse contexto, o delineamento de um currículo voltado para a formação básica, em consonância com a educação profissional, tornou-se urgente e, assim, os IFs, com base no Parecer CNE/CEB 15/98, estabelece um currículo integrado, cuja construção visa a atender às demandas de um perfil profissional, como também, ao desenvolvimento de competências básicas para a vida e às relações sociais.

Com base nessas reflexões e cientes da importância do desenvolvimento das competências linguísticas para a formação do perfil desse indivíduo é que, em 2018, propusemos o projeto "Entre contos" que foi desenvolvido com duas turmas do terceiro ano do Instituto Federal de Educação, Ciência e Tecnologia da Paraíba, Campus Cajazeiras, mais especificamente com as turmas dos cursos integrados ao Ensino Médio em Edificações e Eletromecânica. O projeto foi desenvolvido em quatro fases: preparação dos alunos para descoberta dos contos; momentos de vivência e apropriação; da leitura à produção; retextualização orientada.

Partimos, pois, do pressuposto de que ao aluno, cujas oportunidades educacionais avancem no sentido de promover estratégias voltadas à ampliação de suas capacidades linguísticas, será dada a possibilidade de desenvolver-se em todos os outros campos do conhecimento, visto que todos são entrecruzados pela língua e, assim, o letramento é condição para o bom desenvolvimento social e individual.

Apresentamos, enfim, os resultados do projeto citado, cujo objetivo situou-se em promover situações de interação com os textos literários na perspectiva do desenvolvimento das capacidades de ler, escrever, discutir, analisar, refletir, estabelecendo os entremeios necessários entre os diversos contextos imbricados na compreensão e construção dos textos.

Assim, iremos detalhar todo o processo desenvolvido até a construção do livro resultado dele. Para tanto, faremos também um recorte teórico que fundamentou a proposta de intervenção, fundamentada em contribuições teóricas das áreas da Linguística textual, do letramento literário, no Método Recepcional de Ensino de Literatura e em teorias de retextualização.

\section{Bases para a construção da ação interventiva}

Historicamente, quando ocorreu a criação dos CEFETs, os alunos ingressavam nos cursos técnicos cientes que ali estariam para aprender uma profissão e, neste sentido, os currículos eram direcionados especificamente a este fim. Todavia, assim como a sociedade constrói demandas a partir de suas necessidades e mudanças, os IFs vêm 
atender um novo perfil de aluno, para o qual a formação apenas para exercer atividades profissionais específicas tornou-se insuficiente.

Segundo o PPC do curso integrado (IFPB, 2006, p. 17), a construção do currículo é voltado para à formação do

[...] profissional habilitado com bases científicas, tecnológicas e humanísticas para o exercício da profissão, numa perspectiva crítica, próativa, ética e global, considerando o mundo do trabalho, a contextualização sócio-político-econômica e o desenvolvimento sustentável, agregando valores artístico-culturais.

Por esse limiar, nesse processo de integração não há como desconsiderar a proposição de que o currículo especificamente "destacará a educação tecnológica básica, a compreensão do significado das ciências, das letras e das artes; o processo histórico de transformação da sociedade e da cultura; a língua portuguesa como instrumento de comunicação, acesso ao conhecimento e exercício da cidadania"(LDB, artigo 36, Inc. I) como também a primeira diretriz definida para que as escolas do ensino médio organizem "os currículos, as metodologias e as formas de avaliação"- que "o educando demonstre domínio dos princípios científicos e tecnológicos que presidem a produção moderna" (Artigo 36, $1^{\circ}$, Inc.I).

Com base nesta nova moldagem, as disciplinas do chamado núcleo básico do ensino assumem o seu devido lugar nos currículos dos cursos integrados ao ensino médio dos Institutos Federais de todo o Brasil, de modo a proporcionar uma formação não mais apenas para o exercício do trabalho, mas para a integração social, cultural e, sobretudo, para o exercício da cidadania.

O Ensino de Língua Portuguesa perde o caráter de disciplina instrumental e passa a representar um papel de relevância na formação desses alunos. Dessa forma, considerando que a vida é permeada pela escrita em todas as suas manifestações, assim como afirma Cosson (2006), as relações que permeiam os dias atuais estabelecem exigências que requerem situações de aprendizagem voltadas ao desenvolvimento de habilidades e competências linguísticas através das quais os falantes podem interagir em situações comunicativas.

Com base nesses aspectos, o projeto do curso integrado ao ensino médio (IFPB, 2006) constrói uma grade na qual a disciplina de Língua Portuguesa está inserida em todos os anos do Ensino Médio Integrado e tem como objetivos fundamentais promover um projeto de ensino voltado a:

Compreender a língua materna em seus diversos níveis, contemplando a variante considerada padrão culta, nas expressões oral e escrita, como elemento que traduz informações sobre um mundo real e concreto nas diversas ordens de conhecimento humano: científicos, culturais, humanísticos e tecnológicos. Preparar para o mundo do trabalho e para o exercício da cidadania, permitindo a formação do indivíduo ativo, pensante e flexível que através da linguagem possa expressar sua sensibilidade, formar e transformar a si e ao mundo (IFPB, 2006, p. 19).

Frente a esse propósito, não cabe ao fazer pedagógico, dentro do contexto dos IFs, práticas educativas já ensejadas, em outras palavras, pautadas apenas em práticas reprodutivas de saberes constituídos socialmente, mas na construção e ressignificação 
desses e de outros conhecimentos. Inicialmente, pensar na fragmentação do ensino de língua portuguesa foi a primeira reflexão. Não se admite, pois, distinguir o que são aulas de leitura, de escrita, de literatura, de gramática, enfim, como dividir o ensino de um único objeto, ou seja, a língua portuguesa.

A esse respeito, Antunes (2014) enfatiza que o principal objetivo desse direcionamento dado ao ensino é a aprendizagem efetiva de leitura e escrita, mas sempre agregados aos sentidos e intenções dos textos, jamais deles desagregados. Neste ínterim, esse direcionamento didático deve transcender os saberes imediatistas, de valores práticos ao exercício da cidadania, o qual requer o desenvolvimento de habilidades e competências mais amplas, haja vista que "[...] funciona como instrumento de afirmação e de participação social do sujeito na vida de sua comunidade" (ANTUNES, 2014.p. $61)$.

Ocorre, pois, um confronto entre os universos do imediato e do surreal, entre a reflexão sobre a realidade e àquela apresentada nas histórias, nos livros e, a esse respeito, Cosson (2006, p. 17) explicita que cabe à literatura "[...] tornar o mundo compreensível transformando a sua materialidade em palavras de cores, odores, sabores e formas intensamente humanas".

Esse confronto é vivenciado diariamente através dos discursos discentes em busca de significação para a leitura, sobretudo para a literária. Com base nessa reflexão, ou seja, na importância da literatura para a compreensão do mundo e, num movimento cíclico, do desenvolvimento de habilidades e competências de leitura e escrita para a compreensão da literatura, é que promovemos o projeto "Entre contos".

O projeto foi fundamentado nos preceitos de letramento, isto é, na designação de ações ou práticas sociais da escrita que envolvem a capacidade e os conhecimentos, além dos processos de interação e das relações de poder, por sua vez, relativas ao uso da escrita em contextos e meios determinados (STREET, 2003). Ademais, Sousa; Corti; Mendonça (2012, p. 17) ressaltam que o letramento pode ser compreendido como um "[...] conjunto de práticas sociais mediadas pela leitura e/ou pela escrita" e, nesse sentido, cabe à escola estimular a interação dos alunos com esse universo, inseri-los nas práticas comunicativas e sociais mediadas pela leitura e escrita.

De forma mais específica, atentamos para outro conceito igualmente importante para o projeto desenvolvido, ou seja, o letramento literário é compreendido também como um conjunto de práticas mediadas pela leitura e escrita, mas que fazem uso do texto literário. Em outras palavras, Zappone (2007, p.07) explica que “[...] o Letramento literário pode ser compreendido como o conjunto de práticas sociais que usam a escrita literária, compreendida como aquela cuja especificidade maior seria seu traço de ficcionalidade".

Por esse olhar apontado ao letramento literário, Cosson (2006) enfatiza a importância do trabalho com os textos literários, em sala de aula, mas numa dinâmica integrativa, ou seja, não há aulas de redação, há um mergulho nos textos e a percepção de todos os elementos constitutivos dos mesmos. Um olhar através do qual são percebidos os aspectos estruturais da língua e suas intenções na construção dos sentidos, o entrecruzamentos das informações inscritas no texto e no contexto, enfim, a compreensão da língua em uso. Isso porque,

A experiência literária não só nos permite saber da vida por meio da experiência do outro, como também vivenciar essa experiência. Ou seja, a ficção feita palavra na narrativa e a palavra feita matéria na poesia 
são processos formativos tanto da linguagem do leitor e do escritor. Uma e outra permitem que se diga o que não sabemos expressar e nos falam de maneira mais precisa o que queremos dizer ao mundo, assim como nos dizer a nós mesmos (COSSON, 2006, p. 17).

Gerar essa experiência literária em sala de aula consiste num passo fundamental para que os alunos possam imergir na compreensão dos textos em sua totalidade, como eventos realmente significativos promovido por um verdadeiro contrato interativo entre autor e leitor por meio do texto, visto que, "[...] tanto sujeito como texto delimitam o leque de possíveis leituras de um texto: não há abertura total, porque hipóteses de leitura devem ser verificadas mediante a depreensão dos aspectos formais do texto, nem há apenas uma leitura porque cada sujeito impõe a sua estrutura de conhecimento ao texto" (KLEIMAN, 2011, p. 39).

Essa dimensão construída pelo fenômeno da leitura, conforme Kleiman (2011), pode ser vivenciada através dos mais diversos gêneros textuais. Todavia, é nos gêneros literários que o processo estabelece caminhos ainda mais profícuos devido à riqueza constitutiva desses textos e, pelas relações de verossimilhança, o aluno é convidado a imergir entre o real e o imaginário, aspecto que configura experiências muito significativas intermediadas pela leitura e escrita.

Sob os fundamentos dos pressupostos teóricos já apresentados, partimos para a descrição da primeira fase do projeto desenvolvido, a preparação dos alunos para descoberta dos contos, em outras palavras, a estruturação de um ambiente educacional através do qual ocorreu a estimulação do horizonte de perspectivas, o qual discorreremos na seção seguinte.

\section{0 mergulho no universo dos contos}

O currículo integrado, ao qual já fizemos menção, é construído pelas disciplinas da base comum e as da profissional. Na primeira, estão as línguas portuguesa, inglesa e espanhola, as duas primeiras ofertadas em caráter obrigatório.

Por esse ambiente profissional, muitas vezes as alunos questionam a importância dos estudos, sobretudo aqueles relacionados à Literatura. Trata-se, pois, de um desafio para o docente levar o aluno a compreender a importância desses fazeres pedagógicos para a sua formação e à vida.

Com base neste olhar, fundamentamo-nos na metodologia proposta pelo Método Recepcional de Ensino de Literatura, em Bordini e Aguiar (1993) e, através dele, buscamos desenvolver uma sequência didática de modo a inserir os alunos do terceiro ano do Ensino médio integrado no universo da compreensão da língua.

Como orientação didática, construímos o desenho à ação pedagógica, buscando o modelo de Bordini e Aguiar (1993) para o Método Recepcional que, por sua vez, é composto por cinco etapas: determinação do horizonte de expectativas, atendimento do horizonte de expectativas, ruptura do horizonte de expectativas e ampliação do horizonte de expectativas.

O primeiro passo, referente à determinação do horizonte de expectativas, buscamos conhecer a percepção dos alunos frente à leitura de textos. Esse momento foi guiado por uma roda de conversas: nessa primeira etapa, o professor buscou conhecer o cotidiano dos alunos, sua vida, valores, crenças, lazer, leituras, entre outras particularidades. Nessa fase, ocorreu a apresentação do conto "O corvo", de Edgar Alan 
Poe, através de um vídeo, como ferramenta utilizada para convidar os alunos a mergulhar nesse universo literário. Durante essa etapa, foi possível reconhecer as temáticas que mais chamavam a atenção dos alunos, suas dúvidas e inquietações frente aos textos literários, as crenças por eles trazidas que fundamentavam as buscas textuais e atividades leitoras.

O segundo passo, voltado ao atendimento do horizonte de expectativas, representou o momento em que o professor proporcionou novas experiências com textos literários que atendessem às necessidades/expectativas dos alunos de acordo com os seus conhecimentos. Foi o momento de trazer textos para a sala de aula que despertassem nesses alunos o interesse, promovendo um momento de vivências e apropriação do gênero e das temáticas como desigualdade social, histórias de ficção e terror, reflexões sobre a maldade humana, enfim, a turma foi divida em grupos e a cada um deles, foi ofertado um conto: "Negrinha", de Monteiro Lobato; "Venha ver o Pôrdo-sol", de Clarisse Lispector; "O homem que falava Javanês", de Lima Barreto; "Gato Preto", de Edgar Alan Poe; "Uma vela para Dario", de Dalton Trevisan.

Os alunos foram chamados a fazer a leitura dos contos apresentados e, logo em seguida, convidados a apresentar a turma os textos lidos, ainda como fase de apropriação do gênero, destacando os seguintes aspectos: apresentar a narrativa, discutir o que mais chamou a atenção deles enquanto leitor, que reflexões a narrativa propõe se comparada com a sociedade na qual os alunos estão inseridos.

Após a apresentação, o momento de ruptura do horizonte de expectativas, ou seja, o momento em que são introduzidos novos textos que mexam com as certezas e opiniões dos alunos foi guiado pela reflexão proporcionada pela professora sobre o enquadramento histórico de cada texto. Foi o espaço para levar os alunos a refletirem sobre o papel que a literatura exerce ao levar o leitor a outros tempos e, concomitantemente, perceber o aspecto atemporal que tem a literatura.

Em seguida, convidados ao momento de pesquisa e, tinham como tarefa investigar a que momento da história fazia parte cada obra e que aspectos daquele contexto encontravam-se representados através do texto.

A esse respeito, Bordini e Aguir (1993) destacam que:

Com base na experiência descrita, foi possível vivenciar que a literatura não se esgota no texto. Complementa-se no ato da leitura e o pressupõe, prefigurando-o em si, através de indícios do comportamento a ser assumido pelo leitor. Esse, porém, pode submeter-se ou não a tais pistas de leitura, entrando em diálogo com o texto e fazendo-o corresponder a seu arsenal de conhecimentos e de interesses. O processo de recepção textual, portanto, implica a participação ativa e criativa daquele que lê, sem com isso sufocarse a autonomia da obra (BORDINI; AGUIAR, 1993, p.86).

É importante ressaltar que o trabalho com o ensino aqui apresentado parte do texto e a ele volta, num processo interativo e contínuo, visto que, através das ações proporcionadas, os alunos tiveram a possibilidade de experienciar a língua em uso, seja em atividades de leitura ou escrita, transcendendo da leitura à escrita e à oralidade, "Afinal, ler e escrever são ações que se dão em resposta a textos lidos, ouvidos, imaginados e vividos" (OLIVEIRA, 2014, p. 35).

Ao serem estimulados a buscarem informações que, mais tarde, viriam a contribuir para a troca de ideias, a discussão e a ampliação das bases cognitivas, os 
alunos foram direcionados ao desenvolvimento de habilidades de leitura e escrita das podem podiam lançar mão em quaisquer outras situações que necessitem.

Através dessas ações, a etapa de questionamento do horizonte de expectativas se deu pela análise comparativa sobre o que os alunos já conheciam e o que aparentava ser novo. Esse fenômeno ocorre, pois:

\begin{abstract}
A experiência literária não só nos permite saber da vida por meio da experiência do outro, como também vivenciar essa experiência. Ou seja, a ficção feita palavra na narrativa e a palavra feita matéria na poesia são processos formativos tanto da linguagem do leitor e do escritor. Uma e outra permitem que se diga o que não sabemos expressar e nos falam de maneira mais precisa o que queremos dizer ao mundo, assim como nos dizer a nós mesmos (COSSON, 2006, p. 17).
\end{abstract}

Concordando com o pensamento exposto por Cosson (2006) e atendendo às fases do Método Recepcional, buscamos desenvolver a ampliação do horizonte de expectativas, ou seja, a última etapa do método, momento em que os alunos se conscientizam das alterações e aquisições adquiridas por meio da experiência com a leitura, quando eles percebem que são capazes de obter novos conhecimentos.

A partir desse momento, foi instigante perceber os alunos em busca de novos contos, de novas histórias na tentativa de compreender-se em cada um dos contextos apresentados.

A primeira fase do projeto estava finalizada e os resultados já eram nítidos, visto que o interesse dos alunos no que tange à leitura de textos literários estava em ênfase.

\title{
3. Da teoria à prática
}

Passamos à segunda fase do projeto que foi construída com base no interesse dos próprios alunos. Foi um questionamento levantado por eles, o fato de que qualquer pessoa poderia escrever um conto, expor em palavras sua essência, seus pensamentos, suas reflexões sobre a sociedade na qual está inserido.

Acolhemos a proposta visto que, além de proporcionar a condição de fazer-se leitor-ativo, a atividade gerou a valorização de outras capacidades como destaca Oliveira (2014, p. 35) ao afirmar:

Nessa situação, ouvir o aluno significa valorizar o saber e a cultura que ele traz para a escola, significa envolvê-lo no processo educativo, dividindo com ele responsabilidades, tarefas e formas de sentir (entusiasmo, desejo, cansaço, tristeza, alegrias, sucesso, incertezas). Trata-se de uma forma de atuar na construção da autonomia tão desejada por todo cidadão; de estudar, aprender, ensinar e conhecer 'com o corpo inteiro', no dizer de Freire ([1993] 2002); de atribuir sentido ao mundo objetivo e social, pensando, agindo e sentindo com o outro. Além disso, a interação na modalidade falada, seja em conversas, seja em discussões e debates, favorece não só a troca de informações assim como a partilha de saberes, fornecendo, adicionalmente, subsídios para a prática da escrita. Isso apenas ocorre se pensarmos leitura e escrita como atividades complementares: não há leitura sem textos (escritos ou não), da mesma forma que não se imagina escrita sem atos de leitura. 
Cientes desses aspectos abordados, foi o momento de levar aos alunos a reflexão de que o processo de escrita iria requerer deles uma reflexão sobre os elementos constitutivos do gênero conto.

Foi mais um momento de se fazer um aluno pesquisador e, com base nesse propósito, cada grupo foi em busca de informações que os ajudassem a compreender os aspectos que caracterizaram o gênero, pois, na visão de Oliveira (2010), a escrita pode ser definida como um processo através do qual ocorre a interação entre conhecimentos enciclopédicos, percepções semânticas e pragmáticas, conhecimentos textuais e construções lógicas, todos materializados no código escrito.

As pesquisas realizadas pelos alunos em fontes diversas e escolhidas por eles, em sua grande maioria em enciclopédias digitais, foram trazidas para a sala de aula e, sob a orientação do professor, essas informações discutidas e sistematizadas coletivamente. Através desse direcionamento, os alunos organizam os aspectos constitutivos do gênero conto.

Com base em Antunes (2016, p. 116), guiamos a organização do processo de escrita dos contos baseando-se nas competências requeridas voltadas à autoria. Foram, pois, estabelecidos os passos a serem seguidos durante todo o processo.

O processo inicial consistiu em:

[...] reflexão e de análise do próprio processo de escrever. Essa reflexão pode acontecer antes e durante as atividades e deve incidir sobre o processo mesmo da escrita, seus pressupostos, condições específicas de efetivação, relações com a oralidade e as convenções a que está submetida. Essa reflexão poderá favorecer uma compreensão mais consistente da atividade de escrever [...] (ANTUNES, 2016, p. 116).

Esse momento foi representativo de um pré-planejamento, através do qual a roda de conversa elegeu quais as temáticas que poderiam ser abordadas nos contos, para que iriam escrever aquele texto, se ele teria alguma função social.

Seguidamente, com base na análise dos aspectos constitutivos que estabelecem características relativas ao gênero conto, passamos ao segundo passo na busca pelo desenvolvimento da competência escrita, ou seja, pela prática do texto planejado e revisado.

Foi o momento destinada ao planejamento do texto e, como foi um trabalho individual, cada aluno teve o espaço para fazer o desenho do seu texto, estabelecendo qual seria o conflito, o espaço, tempo, personagens, enfim, todos os indicativos para construção do texto.

Após a produção, cada aluno foi orientado a ser avaliador do próprio texto, seguindo um processo de reflexão sobre a própria escrita. De forma coletiva, alunos e professor construíram uma ficha avaliativa e, segundo os critérios estabelecidos, cada um analisou o seu próprio texto para, em seguida, ocorrer a análise do professor.

Nessa ficha, foram contemplados os seguintes aspetos:

- Meu texto está claro, ou seja, ocorre uma sequenciação de dados e informações de modo que o leitor o entenda?

- Meu texto está interessante, de modo que o leitor tenha interesse em permanecer nele e ir até o fim?

- Meu texto apresenta os aspectos que o caracterizem como um conto? 
- Meu texto atende aos critérios de coesão e coerência?

- Meu texto está escrito em língua padrão, salvo os casos em que o uso de língua não padrão está a serviço da construção de uma ideia?

Em seguida, todos os contos foram analisados pela professora e, através do recurso de revisão do word, os textos foram devolvidos aos alunos para uma segunda revisão, através da qual podiam refletir sobre adequação ao gênero, aspectos linguísticos, criatividade, clareza, enfim, todas as orientações foram individualizadas, apresentadas em balões que versaram sobre todos os aspectos de textualização e orientavam o aluno sobre os direcionamentos para a retextualização.

Ao final desse trabalho, o resultado foi a produção de um e-book, construído pelos alunos. A construção da capa também foi coletiva, visto que o título deveria contemplar a essência das histórias contidas. Assim, como no título "Contos para rir, assustar-se e ser feliz" demonstram as temáticas mais presentes nos contos, ou seja, humor, horror, suspense.

A capa foi produzida pela aluna Samira Gabriely Ferreira Veras, que se prontificou para a atividade, e colocada para aprovação pela turma.

Figura 1 - Capa do livro produzido

Fonte: desenho de

Ferreira Veras

Os contos foram publicados por uma sendo composto o $e$ contos. Esses foram os e publicados.

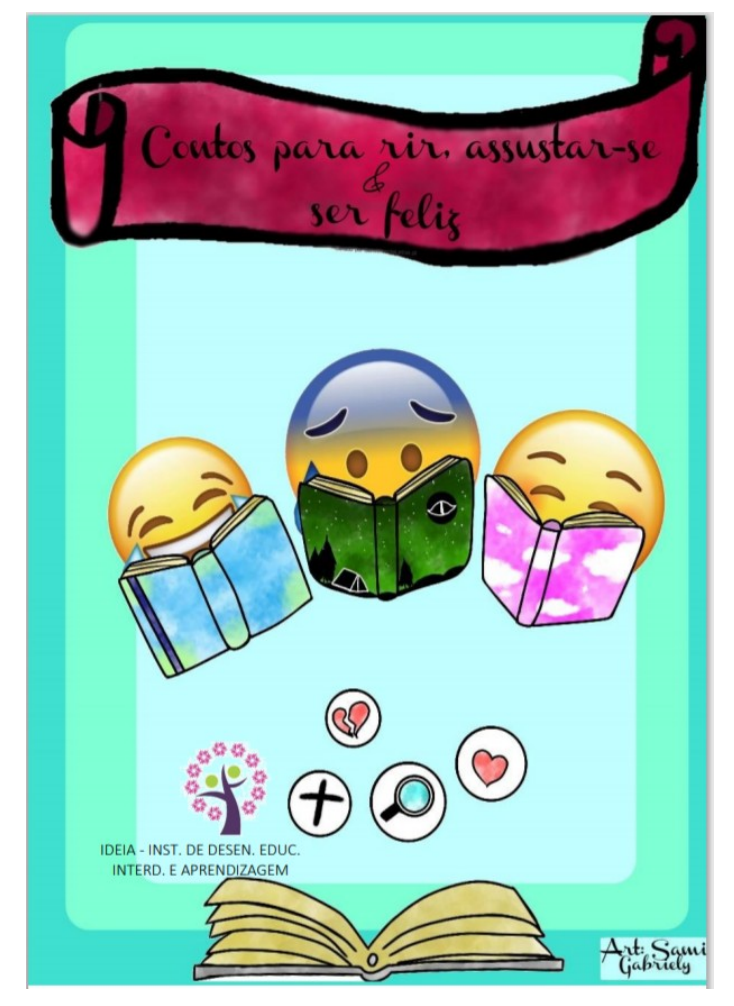

Samira Gabriely

organizados $\mathrm{e}$ editora local, book por 39 contos produzidos

QUADRO 1 - Contos publicados na obra "Contos para rir, assustar-se e ser feliz"

Adrielle Menezes Souza Alef Lenoan Soares Dantas Mota Andressa Fernandes Pinheiro Anne Karoliny Varele da Silva 


\begin{tabular}{|c|c|}
\hline IDENTIDADE QUASE CORROMPIDA & Maria Bianka Pereira \\
\hline O INESPERADO & Brenda Laís de Oliveira Lima \\
\hline DEPOIS QUE PERDE & Bruna Cipriano de Oliveira \\
\hline UM SONHO RUIM & Bruno Macena do Nascimento \\
\hline VEDADOS CLANDESTINAMENTE & Daniel Barbosa \\
\hline O ESTRANHO & Danyllo De Alencar Pereira \\
\hline AS VOZES QUE DESTROEM SONHOS & Danny Hellem Pereira de Freitas \\
\hline O TRISTE FIM DO CÃO TINHOSO & Edgley Silva \\
\hline SEJA LIVRE, KATHERINE & Êmika Vitória Tavares Coêlho \\
\hline O SENTIDO & Euclides Felix da Silva Neto \\
\hline BOI DA SORTE & Fillipe Alves da Silva \\
\hline A SORVETERIA DE SEU JOÃO & Francisco Emanoel Pereira de Sousa \\
\hline O INESPERADO & Jônata da Silva Juvêncio \\
\hline NA SEXTA-FEIRA & Jose Eudisvam Dos Santos Santana \\
\hline FLORES PARA CLOTILDE & José Thales de Souza Gomes \\
\hline O AMIGO IMAGINÁRIO & Julio Johnathan Lacerda Silva \\
\hline ÚLTIMA CARTA & José Layon Fernandes da Silva \\
\hline O QUARTO & Lucas Daniel Melo Feitoza \\
\hline NEVASCA NO SERTÃO & Luís Carlos de Oliveira \\
\hline I HAVE A SECRET & Maria Rita Batista Abrantes \\
\hline A MULHER SILICONE & Mateus Alves Leite \\
\hline INDECISÃO & Mateus Lenilson Barbosa da Silva \\
\hline A DAMA NO MILHARAL & Moacir Braz da Silva Neto \\
\hline 50 ANOS & Nadja Abrantes Ferreira \\
\hline O ASSASSINATO DO REI & Nataliane Vieira Pereira \\
\hline O MISERÁVEL DIA & Maria Olga Soares Cabral \\
\hline UM CACHORRO E UMA FAMÍLIA & Rhayalla Duarte de Souza \\
\hline A FLORESTA & Ronald Batista da Silva \\
\hline A CONFISSÃO DE BERNARDO F. & Ryan de Oliveira Muniz \\
\hline UM DIA DE DETETIVE & Samira Gabriely Ferreira Veras \\
\hline O TRISTE FIM DE ALBERTO CAEIRO & Samuel Wirlley de Araújo Pires \\
\hline AVENTUREIROS & Thalia \\
\hline CONTO & Tálysson Alves da Silva \\
\hline O AMOR ESQUECIDO & Wirnna Silva Rolim \\
\hline $\begin{array}{l}\text { NOSSAS DECISÕES TÊM O PODER DE } \\
\text { NOS DESTRUIR }\end{array}$ & Yohan Figueireido de Sena \\
\hline
\end{tabular}

Fonte: Produto da intervenção didática

Após a finalização e divulgação do trabalho, foi muito significativo o fato dos alunos demonstrarem maior interesse pela leitura literária, aspecto que demonstrou a importância desses direcionamentos. Pode-se destacar que o processo de desenvolvimento das competências da escrita só foi possível a partir da consideração dos gêneros textuais, da educação crítica e do trabalho em parceria entre professor e alunos. Desenvolver um clima de interação e reflexão crítica foi uma das principais ferramentas pedagógicas que, por sua vez, contribuíram qualitativamente nas atividades de escrita.

Neste sentido, ancorados em Kleiman (2006), seguimos todos os passos de produção textual considerando reflexão, planejamento, análise, produção e reescrita, com base no letramento, na realidade sócio-histórica dos discentes envolvidos no projeto em questão e, sobretudo, nas práticas mediadas nos processos de ensino e aprendizagem.

Por este motivo, destacamos que o ensino só se torna significativo quando o docente,

[...] envolve a garantia da aprendizagem pelo aluno, requer a compreensão de sua área específica de atuação e sua significação social e exige múltiplos saberes de ordem pedagógica como a organização do currículo, 
conhecimento do Projeto Político- Pedagógico, planejamento, avaliação, entre tantos outros (NOGUEIRA; LIMA, 2012, p. 5).

Convém destacar que embora estes tipos de práticas de leitura, escrita e reescrita estejam inseridos nos documentos oficiais de ensino de língua materna, Soares e Cunha (2010) ressaltam que estas práticas devem ser inseridas no contexto de formação de professores de língua materna e, neste sentido, precisamos refletir sobre o processo de formação de professores no Brasil com o objetivo de atingir à práxis em sala de aula.

Portanto, é preciso refletir sobre este processo considerando os documentos oficiais de ensino (BRASIL, 1988, 1996, 2005, 2017) e das implicações destes documentos na formação docente. Neste sentido, é preciso estreitar os vínculos entre formação superior e atuação na educação básica de modo crítico e reflexivo, pois, somente assim, teremos uma transformação social com base na formação crítica e na diminuição das desigualdades sociais. Não podemos esquecer que trabalhar com discurso significa atuar diretamente na construção da autonomia e da criticidade dos discentes.

A este respeito, Ribeiro (2014), acrescenta que o letramento deve ser o ponto de partida para desenvolver as competências linguístico-discursivas nos discentes de educação básica. Dessa maneira, faz-se necessário ensinar não somente a escrever e compreender os diversos gêneros textuais, mas, sobretudo, entender as esferas de circulação e, principalmente, os efeitos dos múltiplos sentidos destes gêneros dentro as sociedade.

Compreende-se, portanto, que:

[...] na vida cotidiana, eventos e práticas de letramento surgem em circunstâncias da vida social ou profissional, respondem a necessidades ou interesses pessoais ou grupais, são vividos e interpretados de forma natural, até mesmo espontânea; na escola, eventos e práticas de letramento são planejados e instituídos, selecionados por critérios pedagógicos, com objetivos predeterminados, visando à aprendizagem e quase sempre conduzindo a atividades de avaliação (SOARES, 2004, p. 106).

É com base nestes preceitos teórico-epistemológicos que Mortatti (2004), defende que as práticas educacionais, independentemente do componente curricular, devem se basear nas teorias do letramento, pois, somente assim, contribuiremos ativamente na formação de sujeitos críticos para vida em sociedade e na construção da autonomia dos mesmos.

Embora ainda não tenhamos os resultados esperados de aprendizagem em língua portuguesa, quando comparados com avaliações internacionais de outros países falantes da mesma língua, a exemplo de Portugal, as reflexões sobre melhoria da aprendizagem têm gerado práticas exitosas como a que relatamos, de modo sintético, no presente trabalho.

Dessa maneira, consideramos que envolver os discentes no universo da leituraescrita de modo crítico é um dos principais objetivos do ensino de língua materna sendo, portanto, um constante desafio, uma vez que não existe receita pronta para ensinar e é justamente por isto que a docência é desafiadora e encantadora ao mesmo tempo.

\section{Considerações Finais}


Formar para autonomia é um dos principais desafios no ensino no cenário nacional. Estamos constantemente envoltos em múltiplos discursos e práticas que influenciam diretamente nossa atuação do mundo e nas esferas sociais.

Para que esta atuação ocorra de modo crítico, o docente de língua materna tem um papel primordial por trabalhar com discurso e, dessa maneira, colaborar na construção das competências linguísticas na leitura, escrita, compreensão e interpretação de texto.

Embora separemos estes setores da linguagem, na prática, ou melhor, na práxis docentes, todos devem funcionar de modo colaborativo. Em outras palavras, podemos e devemos trabalhar leitura e escrita de modo relacionado, pois, somente assim, contribuiremos na formação crítica dos discentes da educação básica.

Neste sentido, precisamos planejar nossas sequências didáticas considerando como ponto de partida a realidade sócio-histórica dos nossos discentes e o contexto que a instituição de ensino se encontra inserida. Nesta relação dialética, construiremos situações reais de interação e, por conseguinte, podemos consolidar a relevância da aprendizagem de língua materna com base nos gêneros textuais e no letramento.

Dessa maneira, o presente trabalho, ainda que de modo sintético diante da dimensão do projeto executado, socializa os resultados de práticas exitosas na produção de textuais de discentes do Instituto Federal da Paraíba - IFPB. Destaca-se que este resultado só foi positivo diante do planejamento prévio e de inúmeras reflexões sobre os objetivos de ensino de língua portuguesa. Além disso, a participação crítica, ativa e consciente dos discentes foi de suma relevância para a consolidação do $e$-book que surgiu do interesse dos mesmos e, principalmente, da percepção dos discentes sobre o papel social da escrita, dos gêneros textuais e da interação crítica no mundo considerando o discurso enquanto artefato sociocultural que constrói tudo que existe ao nosso redor.

As temáticas abordadas nos 39 contos produzidos se relacionam a aspectos da própria cultura, a experiências, como também, aos próprios conflitos vivenciados pelo período da adolescência, em outras palavras, demonstram momentos de humor, relatos de decepções sociais e amorosas, a imaginação na forma do terror, enfim, os contos se relacionaram a temáticas diversas, oscilando entre o real e o imaginário.

Com base nessa reflexão, ratificamos a importância de pensar no ensino de língua como uma atividade que envolve, portanto, os diversos fatores que implicam na construção crítica da autonomia, do ensino e, principalmente, de práticas pautadas na práxis, pois, somente assim, podemos construir modelos propostas de ensino que, por sua vez, sejam multiplicadas e adaptadas aos diversos contextos de ensino em um país tão multicultural como o Brasil.

Diante do exposto, esperamos, portanto, contribuir com a práxis em sala de aula ao compartilhar uma das muitas possibilidades de ensino de língua materna com base nos gêneros textuais, ancorados nas teorias dos letramentos e, principalmente, com foco na construção crítica da autonomia dos discentes considerando as aprendizagens significativas decorrentes desta produção textual. 


\section{Referências}

ANTUNES, I. Gramática contextualizada. São Paulo: Parábola, 2014.

ANTUNES, I. Práticas Pedagógicas para o Desenvolvimento das Competências de Escrita. In: COELHO, F. A.; PALOMANES, R. [orgs]. Ensino de produção textual. São Paulo: Editora Contexto, 2016. p. 9-22.

BRASIL. Linguagens, Códigos e suas Tecnologias: orientações curriculares para o Ensino Médio. Brasília: MEC, 2006.

BRASIL. PPP do Curso de Edificações Integrado. IFPB, 2006.

COSSON, R. Letramento literário: teoria e prática. São Paulo: Contexto, 2006.

KLEIMAN, A. Leitura: ensino e pesquisa. 4. ed. Campinas - SP: Pontes Editores, 2011.

KLEIMAN, A. Texto e Leitor: aspectos cognitivos da leitura. Campinas: Pontes Editores, 2011.

OLIVEIRA, L. A. Coisas que todo professor de português precisa saber: a teoria na prática. São Paulo: Parábola Editorial, 2010.

SOUZA, A. L. S.; CORTI, A. P.; MENDONÇA, M. Letramentos no Ensino Médio. São Paulo: Parábola Editorial, 2012.

SOUSA, R. J.; COSSON, R. Letramento literário: uma proposta para a sala de aula. São Paulo: UNESP, 2011.

STREET, B. What's "new" in New Literacy Studies? Critical approaches to literacy in theory and practice. Current issues in Comparative Education, v. 5, n. 2, p. 77-91, Columbia University, 2003.

UCHÔA, S. A. O.; CABRAL, S. A. A.O. (Org.). Contos para rir, assustar-se e ser feliz. Cajazeiras - PB: IDEIA - Inst. de Desen. Educ. Interd. e Aprendizagem, 2019. $140 \mathrm{p}$.

ZAPPONE, M. H. Teoria Literária: Abordagens Históricas e tendências contemporâneas. Maringá: Eduem, 2007.

Recebido em 31 de maio de 2020

Aceito em 23 de junho de 2020 